\title{
ПРОБЛЕМА БЕССОЗНАТЕЛЬНОГО: ФИЛОСОФСКИЕ И МЕДИКО-СОЦИАЛЬНЫЕ АСПЕКТЫ
}

\author{
С. П. Бурцев \\ Московский гуманитарный университет
}

Аннотация: В статье рассматриваются философские и медико-социальные аспекты проблемы бессознательного.

Текст доклада автора на Всероссийской научной конференции «Культура между Логосом и Мифом: к проблеме бессознательного (к 80-летию А. Э. Воскобойникова)», которая прошла в Московском гуманитарном университете 26-27 октября 2017 года.

Ключевые слова: бессознательное; психическая деятельность; подсознание; 3. Фрейд; посттравматическое стрессовое расстройство

\section{THE ISSUE OF THE UNCONSCIOUS: PHILOSOPHICAL, AND MEDICAL AND SOCIAL ASPECTS}

\author{
S. P. Burtsev
}

Moscow University for the Humanities

Аннотация: The paper considers the philosophical, and medical and social aspects of the issue of the unconscious.

The text of the author's speech at the All-Russian Scientific Conference "Culture between Logos and Myth: on the Issue of the Unconscious (dedicated to the 80th anniversary of A. E. Voskoboynikov)", which was held at Moscow University for the Humanities on 26-27 October 2017.

Ключевые слова: unconscious; mental activity; subconscious; S. Freud; post-traumatic stress disorder

Современные экспериментальные науки, в частности, нормальная и патологическая физиология, фармакология, биология, генетика, биохимия, а также клиническая психология, неврология и психиатрия не имеют единого понимания этиологии бессознательного, сути его материального субстрата и механизмов функционирования подсознания. До сих пор в психоанализе, клинической психологии и психотерапии используются гипоте- 
тические теоретические подходы к научно-экспериментальному изучению бессознательного в жизнедеятельности человека. Вследствие этого они проигрывают в убедительности доказательств банальному эволюционному взгляду на формирование психической деятельности человека. Более того, результаты-последствия возможной бессознательной деятельности (именно так оценивал ее реальность 3. Фрейд) невозможно отразить ее же собственным понятийным аппаратом. Мысли, чувства, желания, составляющие основу бессознательной деятельности, описываются только с помощью механизмов сознательной деятельности, например, слов, изложенных разными способами (Фрейд, 2009).

Второй довод 3. Фрейда о наличии подсознания, заключающийся в том, что на огромном пространстве головного мозга только малая часть нейронов способна формировать и контролировать сознательную деятельность человека, а в некоторой части других осуществляются многообразные бессознательные процессы, нуждается в дополнительной трактовке и ряде уточнений (Фромм, 2014ab). В частности, он противоречит тем фактам, которые имеют место у больных, страдающих некоторыми наследственными заболеваниями. Так при аутосомно-рецессивной мезомиелической карликовости в пренатальном периоде развития у плода резко нарушена дифференцировка ряда тканей, в том числе - нервной. Сформированное таким образом слабоумие у пациентов, предполагает уменьшение числа работающих нейронов коры и, соответственно, увеличение массы мозга, занятой подсознательной деятельностью. Однако этого не происходит. Больные малоподвижны, асексуальны, склонны к разнообразным вегетативным нарушениям регуляции работы многих органов и систем. Их эмоции бедны. Аналогичные инверсии в отношении сознания и бессознательного можно наблюдать у пациентов при хромосомных заболеваниях: болезни и синдроме Дауна, синдроме Шерешевского-Тернера, тотальной форме синдрома «суперженщины», особенно при значительном увеличении числа Х-хромосом (более 4-5), а также болезнях обмена, в частности при гликогенозах (болень Кори). Такие же тенденции наблюдаются и при соматической патологии: болезни Паркинсона, микседеме, синдроме Шихена.

Серьезной ревизии должны быть подвергнуты все прежние этиологические концепции бессознательного в связи с внедрением в клиническую практику экстракорпорального оплодотворения и многочисленных технологий использования стволовых клеток.

Значение бессознательного у человека можно отчетливо проследить при внимательном изучении двух видов патологии: неврозы и посттравматическое стрессовое расстройство. Заболеваемость ими увеличивается в последние годы огромными темпами. Все клинические формы неврозов и 
Научные труды Московского гуманитарного университета 2018 № 3

посттравматическое стрессовое расстройство (ПТСР) имеют ярко выраженную медико-социальную причинность и могут развиваться в любом возрасте. Оба эти заболевания объединяет то, что нарушается взаимодействие корковых и подкорковых структур головного мозга. Весьма отчетливо данное явление заметно при истерических и обсессивно-фобических неврозах, а также в рамках психопатической симтоматики ПТСР. Известно, что основными причинами неврозов в настоящее время являются информационная перегрузка граждан (особенно, молодых), высокий темп общественной жизни, сложные межличностные отношения. Вероятно, что в таких условиях афферентные внешние сигналы, поступая через различные рецепторы, не могут быть своевременно адекватно проанализированы и систематизированы с помощью корковых механизмов, а в виде информационного потока, направляются в разнообразные подкорковые структуры и сохраняются, например, в виде определенных конформационно измененных белковых молекул или крупных полипептидов (молекулярная память). При воздействии на человека неврозогенного фактора, когда имеет место перегрузка нейронов коры мозга и ослабляется их контроль за состоянием подкорковых ансамблей, последние высвобождают некий объем, хранящейся в них информации. Это сопровождается немотивированными изменениями поведения, движений, обострением биполярного расстройства, фазовыми состояниями в центральной нервной системе и появлением в ней патологических доминант. Данные симптомы можно трактовать как проявление бессознательного и сделать вывод: чем выше интенсивность стрессорного или невротического воздействия, тем ярче ответные реакции разнообразных подкорковых структур головного мозга, а также то, что только при взаимодействии или нарушенном взаимодействии сознания и подсознания можно обнаружить отчетливые признаки бессознательного.

Причинами ПТСР наиболее часто являются запредельные нервно-психические перегрузки всех персонажей боевых действий или социальных деструктивных процессов, а также непонятные для военнослужащих цели военных конфликтов. Это в последующем служит основой формирования асоциального поведения, приобщения к вредным привычкам, беспорядочным сексуальным связям. На наш взгляд доминирование бессознательного вызывает ряд психофизиологических симптомов: комбатантное поведение, флешбек-синдром, «послелагерную астению» и рентные отношения. Вероятно, что ведущую роль при этом играет таламус и лимбическая система в целом.

В заключении можно отметить, что во многом бессознательное у человека является результатом различных регуляторных процессов на разных уровнях организации живого, как в самой нервной системе, так и на пери- 
ферии: в различных клетках, тканях, органах и системах органов. Конкретно можно назвать ряд регуляторных механизмов: ионная, рецепторная и метаболическая регуляция в клетках, нервная регуляция, осуществляемая вегетативной нервной системой (симпатическая и парасимпатическая), эндокринная и нервная (со стороны центральной нервной системы).

Проблема функционирования бессознательного в различных жизненных ситуациях, представляющая значительный феноменологический и познавательный интерес философского и естественно научного характера, нуждается в дальнейшем теоретическом и практическом развитии. Для этого необходимо создание принципиально новой методологии, позволяющей объективно исследовать различные нервные процессы, как на уровне клетки, так и на уровне целостного организма.

\section{СПИСОК ЛИТЕРАТУРЫ}

Фромм, Э. (2014а) Душа человека. Революция надежды. М. : АСТ. 348 с. Фромм, Э. (2014b) Иметь или быть? М. : АСТ. 320 с.

Фрейд, 3. (2009) Введение в психоанализ. СПб. : Азбука классика. 416 с. Дата поступления: 27.12.2017 2.

Бурцев Сергей Петрович - кандидат медицинских наук, профессор кафедры социологии Московского гуманитарного университета. Адрес: 111395, Россия, г.Москва, ул. Юности, д.5. Тел.: + 7 (499) 374-60-21. Эл. адрес: sergei-burcew@mail.ru

Burtsev Sergey Petrovich, Candidate of Medicine, Professor, Department of Sociology, Moscow University for the Humanities. Postal address: 5, Yunosti St., Moscow, Russian Federation, 111395. Tel.: +7 (499) 374-60-21. E-mail: sergeiburcew@mail.ru

\section{Для цитирования:}

Бурцев С. П. Проблема бессознательного: философские и медико-социальные аспекты [Электронный ресурс] // Научные труды Московского гуманитарного университета. 2018. № 3. URL: http://journals.mosgu.ru/trudy/ article/view/743 (дата обращения: дд.мм.гг.). DOI: 10.17805/trudy.2018.3.6 